\title{
Helping family planning clients self-assess HIV vulnerability: User testing a waiting area chatbot in Zambia
}

Population Council

\section{Recommended Citation}

Population Council. 2021. "Helping family planning clients self-assess HIV vulnerability: User testing a waiting area chatbot in Zambia," ADVICE Results Brief. Washington, DC: Population Council. 


\section{HELPING FAMILY PLANNING CLIENTS SELF-ASSESS HIV VULNERABILITY: USER TESTING A WAITING AREA CHATBOT IN ZAMBIA}

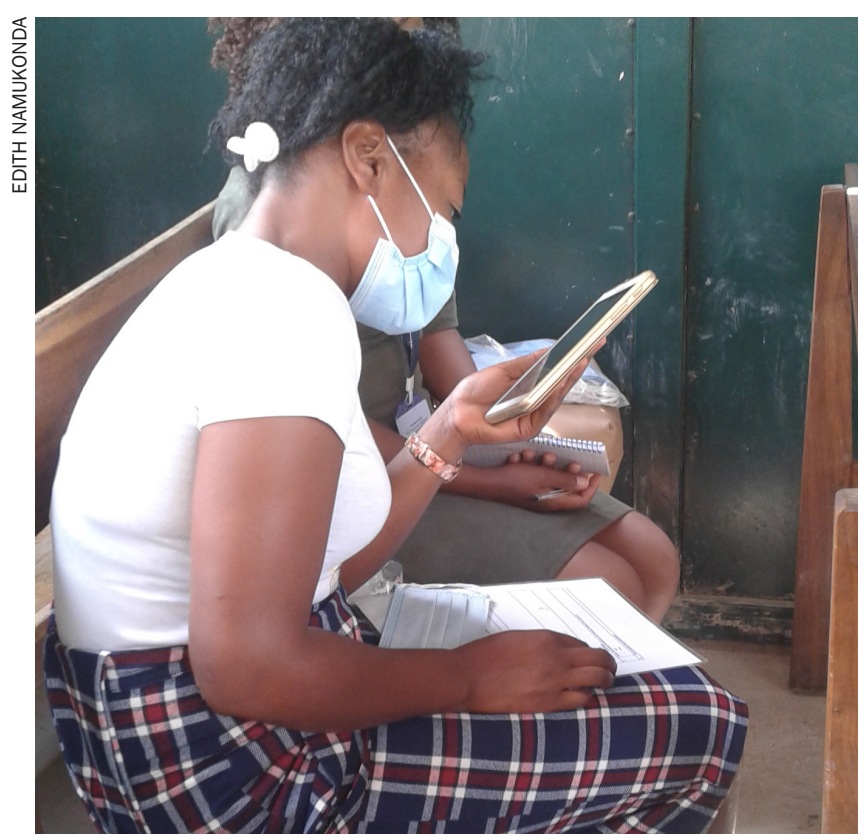

Women who are at risk of unintended pregnancy also may be vulnerable to HIV and other sexually transmitted infections (STIs), and there is international consensus about the importance of integrating HIV and FP services. In FP service delivery settings, traditionally, efforts to incorporate HIV into contraceptive counseling has focused on assessing women's need for and interest in HIV services, such as HIV testing. Less attention has been paid to helping FP clients to assess whether and how their HIV vulnerability may influence their contraceptive choices. For example, some options offer dual protection against pregnancy as well as disease. Ideally, FP providers can help clients decide which method to choose, by helping her think about personal and interpersonal characteristics and behaviors-such as having multiple partners, STI history, substance use, or partners' sexual behaviors-that may increase her vulnerability to HIV. into these topics, and clients may not proactively discuss these potentially sensitive issues.
In recent years, in the United States and sub-Saharan Africa, recognizing the time and resource constraints faced by providers, researchers have tested self-care and self-assessment strategies that FP clients can employ during pre-consultation time (i.e., the time when clients are waiting their turn to see providers). These interventions include interactive mobile applications that walk women through contraceptive options before her provider visit, and web-based tools that introduce FP clients to pre-exposure prophylaxis (PrEP) while they wait their turn to see providers. ${ }^{1-4}$

As part of the Advancing Integrated HIV/Family Planning Counseling with Evidence (ADVICE) project supported by the Bill \& Melinda Gates Foundation, the Population Council developed a web-based digital chatbot designed to engage FP clients to self-assess HIV vulnerability as it relates to contraceptive choices, while in facility "waiting areas" prior to their provider consultations. ADVICE tested the chatbot in health facilities in Lusaka, Zambia, to achieve proof of concept for its use to "prime" clients to contemplate HIV during their pre-consultation time in FP services. 


\section{PROCESS FOR DEVELOPING WAITING-AREA CHATBOT}

ADVICE undertook three overarching steps to develop the chatbot.

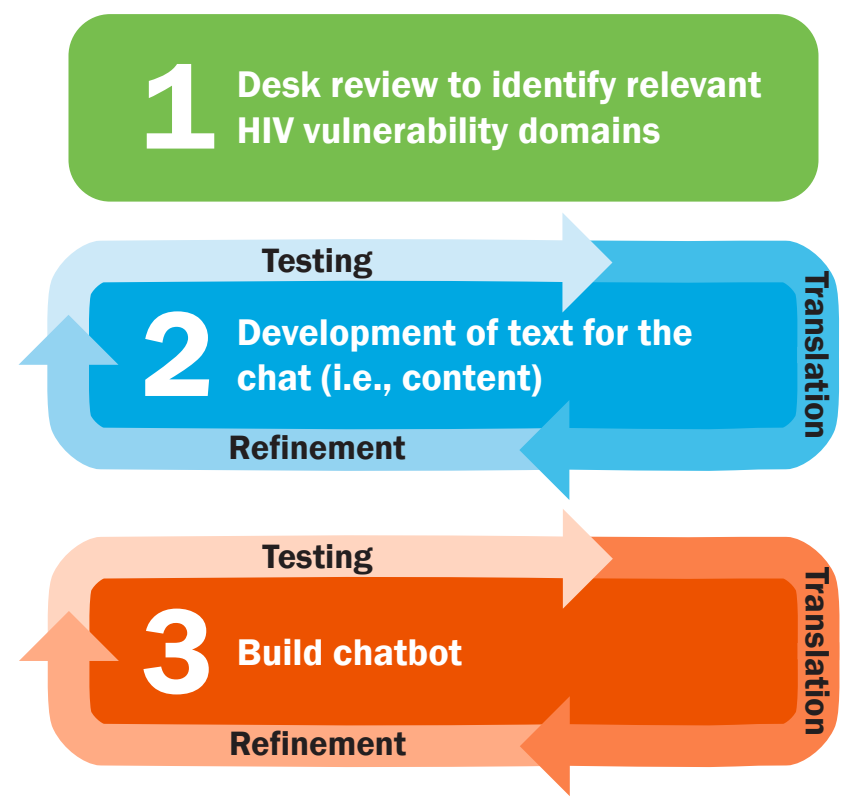

\section{Desk review to identify relevant HIV vulnerability domains}

First, we conducted a desk review to identify key HIV vulnerability domains to incorporate into the chat. Primary sources included published and grey literature, stakeholder conversations, and the online repository of PrEP resources, PrEPWatch. We reviewed 35 HIV vulnerability assessment tools-such as eligibility screening questions for PrEP clinical trials-in which we identified 13 unique HIV vulnerability domains, including sexual behavior, partner characteristics, transactional sex, alcohol and drug use, gender-based violence, and gender norms.

\section{Development of chat content}

We prepared the draft chat content in English, incorporating HIV vulnerability domains identified in the desk review. Three in-person workshops with women of different age groups (15-24, 25-35, and 35-49) were held in Lusaka to test the English text to ensure that it was easily understood, and that the chat flow was logical and engaging. We edited the chat text based on feedback from the workshops, and the chat was then translated into Bemba and Nyanja. A second round of workshops was conducted to verify these translations. Each successive round of review led to iterative edits in all three languages. The final chat content included four modules of content: background on HIV, sexual behavioral risk, partner characteristics, and dual protection (Table 1).
TABLE 1 FOUR MODULES OF CHAT CONTENT

\begin{tabular}{|c|c|}
\hline Module & Illustrative chat \\
\hline $\begin{array}{l}\text { Background on } \\
\text { HIV }\end{array}$ & $\begin{array}{l}\text { Let me give you some background on HIV. } \\
\text { HIV can be acquired through bodily fluids, in- } \\
\text { cluding through sexual contact, and through } \\
\text { breast milk and blood... }\end{array}$ \\
\hline $\begin{array}{l}\text { Sexual behav- } \\
\text { ioral risk }\end{array}$ & $\begin{array}{l}\text { Women who have had a recent STI may also } \\
\text { be at risk of getting HIV. You may be interest- } \\
\text { ed in talking to your provider about how you } \\
\text { can get tested for HIV.... }\end{array}$ \\
\hline $\begin{array}{l}\text { Partner } \\
\text { characteristics }\end{array}$ & $\begin{array}{l}\text { Sometimes, a woman's sexual partner(s) also } \\
\text { is/are having sex with others. Having more } \\
\text { than one partner can increase HIV risk.... }\end{array}$ \\
\hline Dual protection & $\begin{array}{l}\text { Many women would like to prevent pregnancy } \\
\text { as well as avoid getting or passing on HIV. } \\
\text { Some people call this "dual protection".... }\end{array}$ \\
\hline
\end{tabular}

\section{Building the chatbot}

Finally, we selected a chatbot platform and built out the chatbot. Several considerations went into the selection of the final chat platform including geographic availability, data/Internet requirements, timeline, and cost. Based on these considerations, we selected Microsoft Azure Bot Services, which supports interactive pre-scripted conversational chats. We first uploaded the chat content in English and iteratively edited to ensure the sequence of texts was logical and accurate, repeating this review process for the Bemba and Nyanja content. Once the chat content was finalized in all three languages, it was uploaded into the Azure platform.

\section{FIELD TEST OF THE CHATBOT}

We conducted user testing in March 2021 with women in FP clinics in Lusaka to assess the proof of concept for a waiting-area HIV self-assessment chatbot. Leveraging an ongoing partnership between the Population Council and participating sites, ADVICE received Ministry of Health support to conduct user testing in three public FP clinics: Chipata, Chawama, and Kalingalinga clinics.

To identify test users in waiting-areas, the nurse in-charge and Population Council interviewers screened potential participants for eligible age (15 to 49) and basic literacy in any of the three chat languages. Interviewers presented eligible, interested women with an Internet-enabled tablet to engage with the chat. After completing the chat, testers completed an online exit checklist to give feedback on their experience, before or after seeing the provider. A 


\section{ADVICE CHATBOT}

A chatbot is a software application that simulates having a conversation with a human. The ADVICE chatbot was a series of text exchanges, by which users selected responses to scripted questions, with automated content generated in response to their answers.

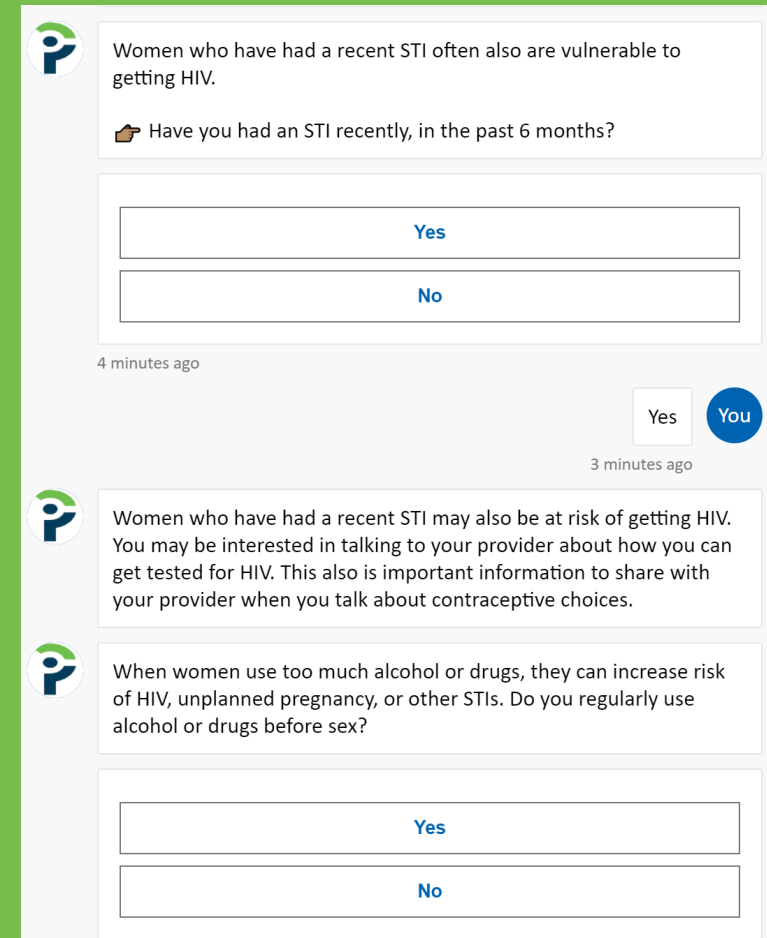

transportation stipend of $\mathrm{K} 6 \mathrm{O}^{1}$ was given to respondents after completing the chatbot and the exit survey.

Initially, due to bandwidth and connectivity issues, it took users a long time to work through the chat content, as the Internet was very slow. To mitigate these issues, interviewers switched from using hotspots to SIM cards, and upgraded bandwidth, which increased Internet speed. A second challenge at some sites was the lack of a dedicated waiting-area space. In these scenarios, women engaged with the chat in other areas in/around the clinic, such as a tent outside or an empty room at the facility.

\section{User feedback}

\section{User characteristics}

Fifty-four women were invited to participate, and 30 completed the chat and exit survey. Of those who were invited to participate and did not complete the chat and exit survey, 13 did not pass the literacy screening. Other reasons for declining included that they were "too busy" and "not interested." Two-thirds of testers were between the ages of 25 and 34. Eighty percent were married or cohabitating, and 80 percent had secondary or more education (Table 2).

\section{TABLE 2 RESPONDENT CHARACTERISTICS}

\begin{tabular}{|lrr|}
\hline Age & $n$ & $\%$ \\
$\quad<18$ & & \\
$18-24$ & 1 & 3 \\
$25-34$ & 9 & 30 \\
$\quad 35+$ & 19 & 63 \\
Marital status & 1 & 3 \\
$\quad$ Single, never married & & \\
$\quad$ Married or cohabitating & 5 & 17 \\
$\quad$ Divorced/widowed & 24 & 80 \\
Highest level of education completed & 1 & 3 \\
$\quad$ Primary or less & & \\
$\quad$ Secondary or more & 6 & 20 \\
\end{tabular}

\section{Feasibility and acceptability}

- $77 \%$ of testers agreed that the chat took just the right amount of time to complete. (Average time in minutes to complete the chat was 29.5, ranging from 11 to 58 minutes.)

- $97 \%$ agreed that it was easy to understand the chat.

- $97 \%$ agreed that using the chat was a good use of time while waiting to see the provider.

- $100 \%$ would recommend the digital chat to someone waiting to see a provider in the waiting area.

\section{Effect on knowledge and provider interaction}

- All women agreed that information in that chat helped them think about how to protect from pregnancy as well as HIV. Of those who saw a provider before taking the exit survey $(n=24)$, nearly all spoke to the provider about HIV because of what they learned in the chat and a majority learned new information, including learning about PrEP for the first time (Figure 1).

${ }^{1}$ USD2.68 


\section{FIGURE 1 EFFECT ON KNOWLEDGE AND PROVIDER INTERACTION $(\mathrm{n}=24)^{*}$}

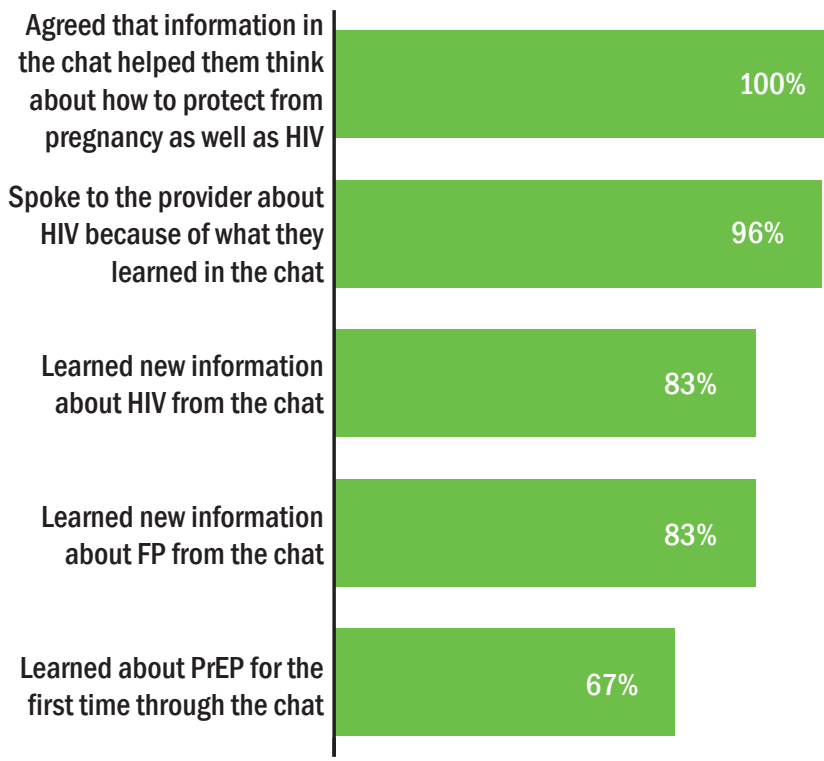

*Among the 24 testers who completed the exit checklist after seeing the provider.

\section{Feedback on experience}

In response to an open-ended question requesting any additional feedback, women expressed positive feedback on the chat experience:

66 The chat has helped me to learn a lot and I would like that other women get this opportunity.

It is a very interesting programme and it should be implemented in all clinics for people who don't know.

I would like this chat to continue for the good future of young women and girls.

\section{LEARNINGS AND FUTURE OPPORTUNITIES}

For FP clients who possess basic verbal and digital literacy, it was feasible for them to engage with a digital chat during their pre-consultation time, learning new HIV information and discussing chat content with providers after the chat. The high levels of positive feedback from test users was promising, and users suggested that the chat was a good use of their wait time. Building on this proof of concept, future initiatives could evaluate whether these types of waiting-area digital interventions improve quality of counseling, or influence FP/HIV behaviors such as method choice or PrEP uptake. In addition, the chat text that ADVICE developed for this proof of conceptwhich squarely focused on the dual HIV and pregnancy prevention needs of FP clients in clinic waiting areas-is content that could readily be adapted and used in other languages, via alternative platforms or devices (including the users' own mobile phone), and in different contexts (such as in community settings).

\section{References}

1. Dehlendorf, C. et al. 2019. "Cluster randomized trial of a patient-centered contraceptive decision support tool, My Birth Control," American Journal of Obstetrics and Gynecology 220(6): 565.e1-565. e12. doi: 10.1016/j.ajog.2019.02.015

2. Dev, R. et al. 2019. "Acceptability, feasibility and utility of a Mobile health family planning decision aid for postpartum women in Kenya," Reproductive Health 16(1): 97. doi: 10.1186/s12978-019-0767-9

3. Hebert, L. E. et al. 2018. "Mobile contraceptive application use in a clinical setting in addition to standard contraceptive counseling: A randomized controlled trial," Contraception 98(4): 281-287. doi: 10.1016/j.contraception.2018.07.001

4. Wilson, W. et al. 2018. "Development of MyPrEP, an integrated preexposure prophylaxis and contraceptive decision support tool for young women in South Africa and Kenya," Contraception 98(4): 367-368. doi: 10.1016/j.contraception.2018.07.118

\section{ACKNOWLEDGEMENTS}

The ADVICE team would like to thank the following entities and individuals for their support of this study: Zambia Ministry of Health-Dr. Andrew Silumesi; Chipata ClinicDr. Victor Liyuma, Ms. Evelyn Tembo, Sr. Margret Nyirenda Velepi; Kalingalinga Clinic-Dr. Thanthwe Mangani, Sr. Ireen Silavwe; Chawama Clinic-Dr. Shula Chanda, Ms. Mutinta Maina Chinkuli, Ms. Olipaah Moolah, Sr. Theresa Phiri; Bill \& Melinda Gates Foundation-Christine Galavotti; and Nivi, Inc.-Ben Bellows.
POPULATION COUNCIL

Ideas. Evidence. Impact
The Population Council confronts critical health and development issues-from stopping the spread of HIV to improving reproductive health and ensuring that young people lead full and productive lives. Through biomedical, social science and public health research in about 50 countries, the Council works with our partners to deliver solutions that lead to more effective policies, programs, and technologies to improve lives worldwide. Established in 1952 and headquartered in New York, the Council is a nongovernmental, nonprofit organization with an international board of trustees. popcouncil.org

Suggested citation: Population Council. 2021. "Helping family planning clients self-assess HIV vulnerability: User testing a waiting area chatbot in Zambia," ADVICE Results Brief Washington, DC: Population Council. 